\title{
E-SPEAK: THE TECHNOLOGY FOR UBIQUITOUS E-SERVICES
}

\author{
Alan H. Karp \\ Hewlett-Packard Laboratories
}

\begin{abstract}
Today, setting up a service to be used over the Internet is difficult, special-case work. Part of the difficulty is that each provider of such a service addresses a common set of problems in a proprietary way. E-speak solves the problems of naming, describing, managing, and controlling access in a manner that makes it easier and safer to allow remote access. With e-speak, we can think of all applications as e-services that we can enlist to solve our problems.

E-speak is the open-source software platform for creating, composing, mediating, managing, and accessing Internet-based e-services. With espeak we can more easily build a world of universal e-services that can be accessed intuitively using a wide array of devices and platforms, from personal digital assistants, to PCs, information appliances, and supercomputers. With e-speak these e-services can interact with each other in order to advertise capabilities, discover other e-services, and ally with each other to offer new functionality, even negotiate to broker, bill, manage, and monitor each other - all in a dynamic, ad hoc, yet secure manner.

This talk will describe the requirements that led to the various features of the e-speak architecture as well as its key abstractions and innovations.
\end{abstract}

